\title{
Correction to: Profitable Production of Stable Electrical Power Using Wind-battery Hybrid Power Systems: A Case Study from Mt. Taegi, South Korea
}

\author{
Sangwook Park ${ }^{1}$ - Gwon Deok Han ${ }^{2}$. Junmo Koo ${ }^{2}$ Hyung Jong $\mathrm{Choi}^{2}$ • Joon Hyung Shim ${ }^{1,2}$
}

Published online: 21 May 2019

(c) Korean Society for Precision Engineering 2019

\section{Correction to: \\ International Journal of Precision Engineering and \\ Manufacturing-Green Technology \\ https://doi.org/10.1007/s40684-019-00037-0}

The original version of this article unfortunately contains a mistake. The acknowledgement section of the above article is incorrect. The correct acknowledgements are as follows:

Acknowledgements This work was supported by the Korea Institute of Energy Technology Evaluation and Planning (KETEP) and the Ministry of Trade, Industry and Energy (MOTIE) of the Republic of Korea (no. 20173010032170), and the Korea Electric Power Corporation (no. R17XA05-57).

Publisher's Note Springer Nature remains neutral with regard to jurisdictional claims in published maps and institutional affiliations.

The original article can be found online at https://doi.org/10.1007/ s40684-019-00037-0.

Joon Hyung Shim

shimm@korea.ac.kr

1 Department of Mechanical Engineering, Stanford University, Stanford, CA 94305, USA

2 School of Mechanical Engineering, Korea University, Anam-ro 145, Seongbuk-gu, Seoul 02841, Republic of Korea 